This item was submitted to Loughborough's Research Repository by the author.

Items in Figshare are protected by copyright, with all rights reserved, unless otherwise indicated.

\title{
Cognition as context (whose cognition?)
}

PLEASE CITE THE PUBLISHED VERSION

http://dx.doi.org/10.1207/s15327973rlsi3101_2

PUBLISHER

(c) Taylor \& Francis

VERSION

AM (Accepted Manuscript)

LICENCE

CC BY-NC-ND 4.0

REPOSITORY RECORD

Potter, Jonathan. 2019. "Cognition as Context (whose Cognition?)". figshare. https://hdl.handle.net/2134/9525. 
This item was submitted to Loughborough's Institutional Repository (https://dspace.lboro.ac.uk/) by the author and is made available under the following Creative Commons Licence conditions.

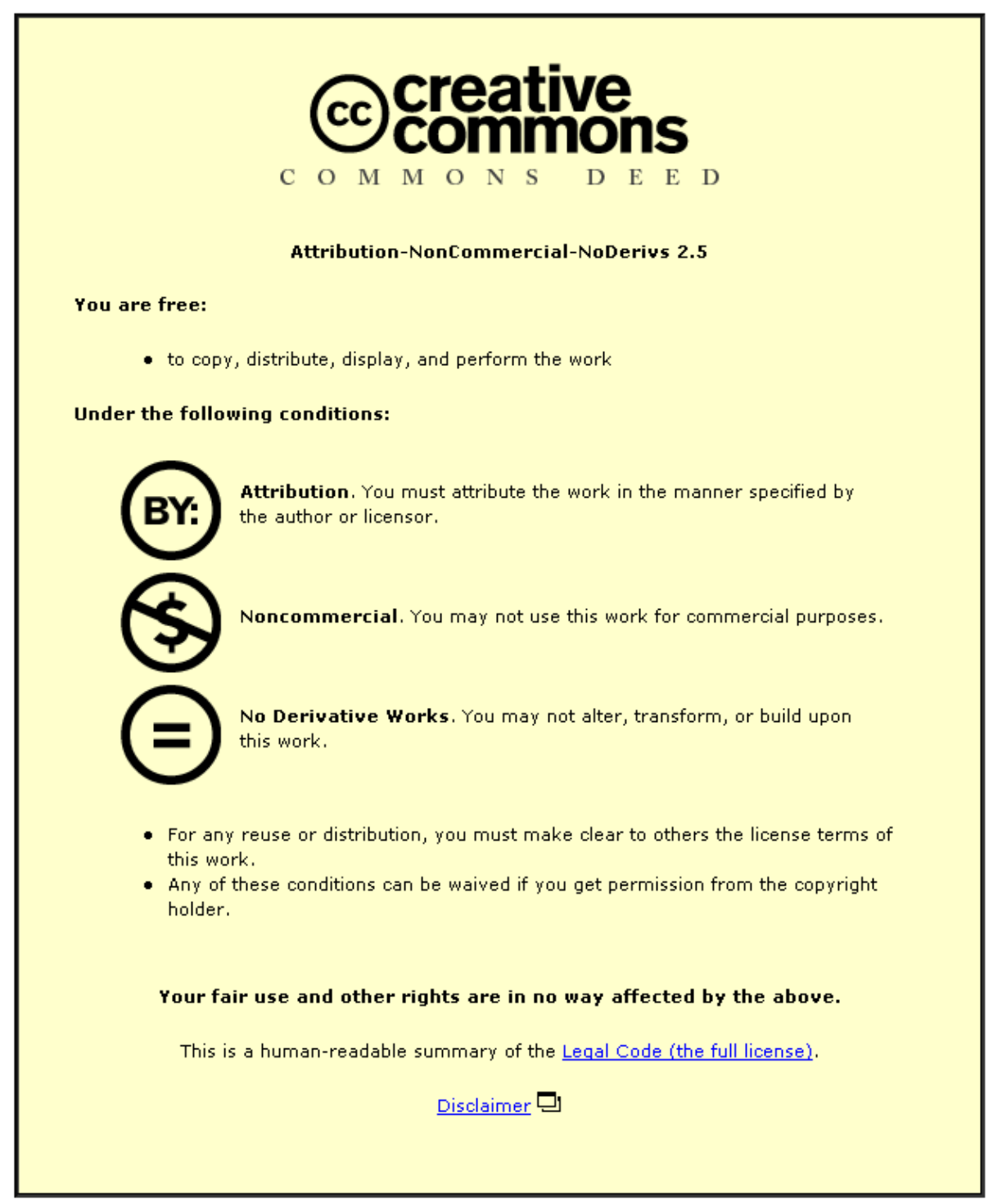

For the full text of this licence, please go to: http://creativecommons.org/licenses/by-nc-nd/2.5/ 


\section{Cognition As ConteXt (Whose Cognition?)}

\section{JonATHAN PotTer}

Discourse and Rhetoric Group

Department of Social Sciences

Loughborough University

Loughborough

Leicestershire, LE11 3TU
Email: J.A.Potter@lboro.ac.uk

Tel: 01509223384

Fax: 01509223944

For: K. Tracy (Ed.) “Text” and “Context” in Analyses of Social Life, special issue of Research on Language and Social Interaction

I would like to thank Derek Edwards, Charles Antaki and Karen Tracy for making detailed comments on an earlier draft of this paper, and Malcolm Ashmore, Michael Billig, Celia Kitzinger and members of the Loughborough Discourse And Rhetoric Group for numerous discussions pertinent to this topic. 
In a series of papers Emanuel Schegloff (1987, 1989, 1991, 1992a, b, 1997) has developed arguments concerning the coherence of analytic procedures for addressing entities that would traditionally have been glossed as ‘social structure' or 'social context'. He argues that 'social context' should be treated as relevant to analysis only insofar as it features as a participants' concern; that is, only insofar as it is invoked, formulated, oriented to, or displayed in actual interaction. Research conclusions should be disciplined by attending to the procedural consequentiality of any claimed contextual particular.

This paper will briefly review Schegloff's argument and pick out some themes that have been highlighted by recent work in discursive psychology (Edwards and Potter, 1992, 1993; Edwards, 1997; Potter, 1996). In particular, it will emphasise the way that cognition, in some form or other, is often treated as a taken-for-granted background in discussions of context. In effect, cognition is treated as the inner stuff of perception, storage and inferences and it is set over against an outer reality of context, which might be events, settings and social structures. However, that reality is typically seen as having its effect via its cognitive perception, representations and processing. The paper will argue that cognition can be subject to some of the same analytic moves as context and that, indeed, in participants' discourse things that analysts have traditionally glossed under the categories ‘cognition' and ‘context' often blur together.

My suggestion is that 'cognition' and 'reality', conventionally the inner and the outer, can be treated in the same way as things which are formulated, attended to, and oriented to in discourse. In this way cognition becomes a topic of discursive study, but is respecified in the process. In the title of a recent paper, Schegloff (1997) asks the rhetorical question Whose Context? This highlights the questionable status of analysts versions of context vis a vis 
those of participants. My subtitle - Whose Cognition? - raises a parallel question with respect to cognition.

\section{SCHEgloff AND THE ANALysis OF Social ConTEXT}

Schegloff's arguments are directed against a wide range of more or less sophisticated treatments of 'context' which treat particulars that might conventionally be glossed as ‘setting', 'culture’, or 'social structure’ as related to interaction insofar as technical analytic connections can be made between the two. The crucial issue is the role of participants' orientations. Given that there are an indefinite number of possible contextual descriptions available for any interaction, how should one particular one be selected as analytically germane. The researcher may have powerful intuitions about the pertinence of gender, say, or a courtroom setting; however, that is not the same as showing that these particulars are actually relevant. After all, there are so many potential descriptions that are correct that a stronger criterion of relevance is needed.

For example, I am currently working at a desk, a PC, in a room, later than scheduled, in response to a request from Karen Tracy, in an Ivory Tower, in the European Union. All these descriptions are in some sense correct - and each might be used to explain some features of my activity. For Schegloff the appropriate analytic discipline is provided by attending to the orientations provided by the participants in their interaction and the procedural consequentiality of the contextual particular for the interaction.

There is an additional subtlety to Schegloff's argument. Even after some contextual description has been demonstrated to be procedurally consequential, there is still a further 
question concerning precisely what element of the context is consequential. For example, it may be that there are particular consequences for the organization of discourse that are associated with being interviewed on a television news programme. However, detailed study might reveal that those consequences do not follow in a unique manner from contributing to 'media discourse', but are instead a consequence of more generic interactional contingencies (such as the 'disinterested’ participation status of the interviewer - Schegloff, 1989; Heritage and Greatbatch, 1991).

Schegloff's arguments promote a view of context that is characteristic of much (but by no means all) work in ethnomethodology, conversation analysis, and some strands of discourse analysis. Here 'context' is treated as something which is constructed, dealt with and oriented to by participants. Features of participants such as their ethnicity, features of the setting, and other 'ethnographic' particulars are not treated as separable factors, which can simply be related to interaction.

Note that this approach to context starts to dissolve the traditional micro-macro distinction. Rather than seeing social structure and context as something prior to, and set over against interaction, a range of conversation analytic work has studied the constitution of social structural phenomena in talk and texts (Heritage, 1997). Indeed, this follows from the general ethnomethodological emphasis on the reflexivity of interaction that regards interaction as pervasively and inescapably context sensitive and context shaping (Heritage, 1984; Wieder, 1974). At the same time, work in a more discourse analytic tradition has studied the construction of social structural notions (versions of society and social process) in talk and texts and how these constructions service a range of interactional and ultimately 
ideological tasks such as presenting inequalities as necessary, natural or acceptable (Billig, 1992; Wetherell \& Potter, 1992).

Note also that this approach does not imply that analysis is being done without ethnographic knowledge as if everything relevant is to be discovered in the talk or text. For one thing, knowledge of a language, which itself is a tremendously rich reservoir of ethnographic understanding, is a prerequisite for any analysis of conversation or discourse. Without it we would be hard pressed to make much sense of self-repair or the management of stake inoculation. However, that does not mean that the analyst's intuition about language or culture takes priority; rather, analysts' expectations are disciplined by the materials that are being studied. This is one of the things that distinguishes conversation and discourse analysis from conceptual analysis (Edwards, 1997; but see Coulter, 1983).

Note further that this approach blurs the distinction between participants’ and analysts' knowledge. Instead, there is an emphasis on the symmetry between participants and analysts. Rather than social context being something that has its effect behind the participants' backs in a way that only the technical skills of analysts can discern, social context is seen as a problem for participants and analysts alike. For the participants it is a practical problem of how to act: has the lesson started? was that an accusation?, and so on; for the analysts the problem is one of using what is displayed in the participants' interaction as a central resource for developing more technical understandings (Drew, 1995a). This is rather different from the kinds of sociolinguistics and discourse studies that Schegloff is criticising in which the analyst's technical knowledge about culture or society is taken to provide an essential resource in the analysis of talk and texts. This is not to claim that discourse and conversation analysis is merely a reformulation of participants' knowledge; rather, it is to emphasise the 
systematically emic nature of such work as it attends to the sense that interaction has for the participants.

\section{Cognition as ConTEXT}

One of the things that is notable for its absence in most discussions of context is explicit discussion of the role of cognition. In their useful overview Charles Goodwin and Alessandro Duranti start with Elinor Ochs' notion that context is 'the social and psychological world in which the language user operates at any given time' (1992, p.6) and they draw on Ochs' listing of potential contextual attributes: setting, behavioural environment, language, and extrasituational context. This discussion of context works against a backdrop of implicit psychological processes. Contextual particulars such as setting or behavioural environment are important because they are perceived, experienced, attended to, understood and so on. Indeed, Goodwin and Duranti divide context into that which is focal, thereby treating it as strongly perceptual, and that which is extrasituational and therefore depends on either background knowledge or memory (of organizations, history, cultural norms and so on).

Much of the discussion of context trades on an implicit cognition/reality distinction. In this implicit view there is a reality of context. This reality is made up of things and events in the world, of history, culture, the institutional setting, bodily orientations, prior conversational turns, and so on. These are all the things that makes context appear to be such a huge and intractable issue in traditional formulations of the context problem (Cook, 1990). This reality is assumed, again often implicitly, to have its effect through psychological processes. That is, it is perceived in real time, and brought into settings via knowledge and memory. This 
distinction is a messy one. Both reality and cognition have been constructed in a wide variety of ways, in different conceptual and theoretical systems. Nevertheless, I hope that others will recognise the widespread use of this distinction, and the close dependence of context and cognition in analytic discourse.

In much sociolinguistic work this cognitivism remains undeveloped and inexplicit.

Occasionally a cognitive approach is more systematized and related to the technical literature of cognitive psychology and cognitive science. Teun van Dijk’s work provides an ambitious example of this approach to context:

contexts are (socially based) mental constructs, or models in memory. Since meaning and other discourse properties are also mentally managed, this also explains the vital link between discourse and context: as subjective representations, mental models of contexts may thus directly monitor the production and comprehension of talk and text. Indeed, without such subjectivity of language users and their minds, the 'same' social contexts would have the same effect on all language users in the same situation, which they obviously have not. ...contexts... need a cognitive definition in order to... explain how social structures can influence discourse structures 'via' the mind of social members (1997, p. 16, emphasis in original).

Or, more pithily, but equally cognitively, Dan Sperber and Dierdre Wilson claim: the set of premises used in interpreting an utterance... constitutes what is generally known as the context. A context is a psychological construct, a subset of the hearer's assumptions about the world (1986, p. 15, emphasis added). 
My general point, then, is that discussions of context typically presuppose some kind of cognitive realm, but this is rarely articulated in an explicit and technical manner. Across social theory, sociolinguistics, critical discourse analysis and discourse studies, a whole thesaurus of cognitive notions appear, from the more everyday - knowledge, belief, view, goal and plan - to the more technical - short term memory buffers, social representations, script processing, category salience and accessibility heuristics. Indeed, the notions of both 'context' and 'cognition' are used to collect together an extraordinarily heterogeneous set of processes and entities.

Schegloff's argument focuses on the management of contextual particulars such as settings, but does not address itself to the role of cognition. For the rest of this paper I will attempt to show how the use of cognition in conversation and discourse work can be susceptible to similar arguments derived from discursive psychology. My argument will have two parts. First, I will suggest that, when dealing with participants' discourse, cognitive notions present the same analytic trouble, and the same analytic temptations, as the conventional building blocks of context: institutional and physical setting, cultural traditions, and so on. Second, I will suggest that they thereby become susceptible to the type of argument that Schegloff has directed at (other features of) context.

\section{Discursive Psychology — Cognition ANd ReAlity}

While social structure and its conceptualization has been a major point of discussion in recent ethnomethodology and conversation analysis (Boden \& Zimmerman, 1991; Drew \& Heritage, 1992; Watson \& Seiler, 1992), cognition has figured much less significantly. There 
has been explicit discussion in Wittgenstein influenced ethnomethodology of cognitive notions and forms of analysis (Coulter, 1990, 1991; Lynch and Bogen, 1996) as well as arguments against cognitivist interpretations of conversational practices (Heritage, 1990/1); however, conversation analysts have often been agnostic with respect to cognitive issues or even willing to consider some integration of cognitive and conversational approaches (Drew, 1995a, b; Mandelbaum \& Pomerantz, 1990; Pomerantz, 1990/1).

Perhaps because of their different disciplinary context (!) a number of social psychologists with an interest in discourse and rhetoric have problematized the role of cognition in social explanation (Antaki, 1994, forthcoming; Billig, 1987; Edwards, 1994, 1997, forthcoming; Edwards \& Potter, 1992; Potter, forthcoming; Potter and Wetherell, 1987; Widdicombe \& Wooffitt, 1995). That is, rather than treating cognition as prior to, and separable from, interaction, it is treated as something that is built in, managed in, and constituted in interaction.

This has direct implication for discussion of context. For if settings are assumed to have their operation through participants' representations, and if extrasituational particulars have their operation through participants' knowledge and memories, then discursive psychological work which shows up the locally occasioned nature of 'representation' and 'memory’ raises major problems. They make problematic the very technical scaffolding that is required to track the effects of traditional contextual notions. My argumentative strategy here will be to show how both the 'outer' world of reality, and the 'inner' world of cognition, enter into analysis through orientations and constructions. Moreover, in participants discourse constructions of the world and cognition are often mutually implicative: cognition (attitude, say, or disinterest) can be managed through descriptions while reality (events, say or actions) can be stabilized 
and managed through a range of cognitive claims and avowals (more descriptions, in this case of mental furniture). Indeed, the notions of cognition and reality only seem so neatly separable in the abstract analytic language of social researchers.

Let me clarify and exemplify these ideas by showing how they can be applied to a particular case.

\section{MANAging Cognition ANd REALity}

In the following extract from a phone call, Skip is talking with Leslie, his wife, about a burglary that happened at their house on the previous day. Leslie is providing further information about the events to Skip. The section I will focus on is in lines 13 to 30.

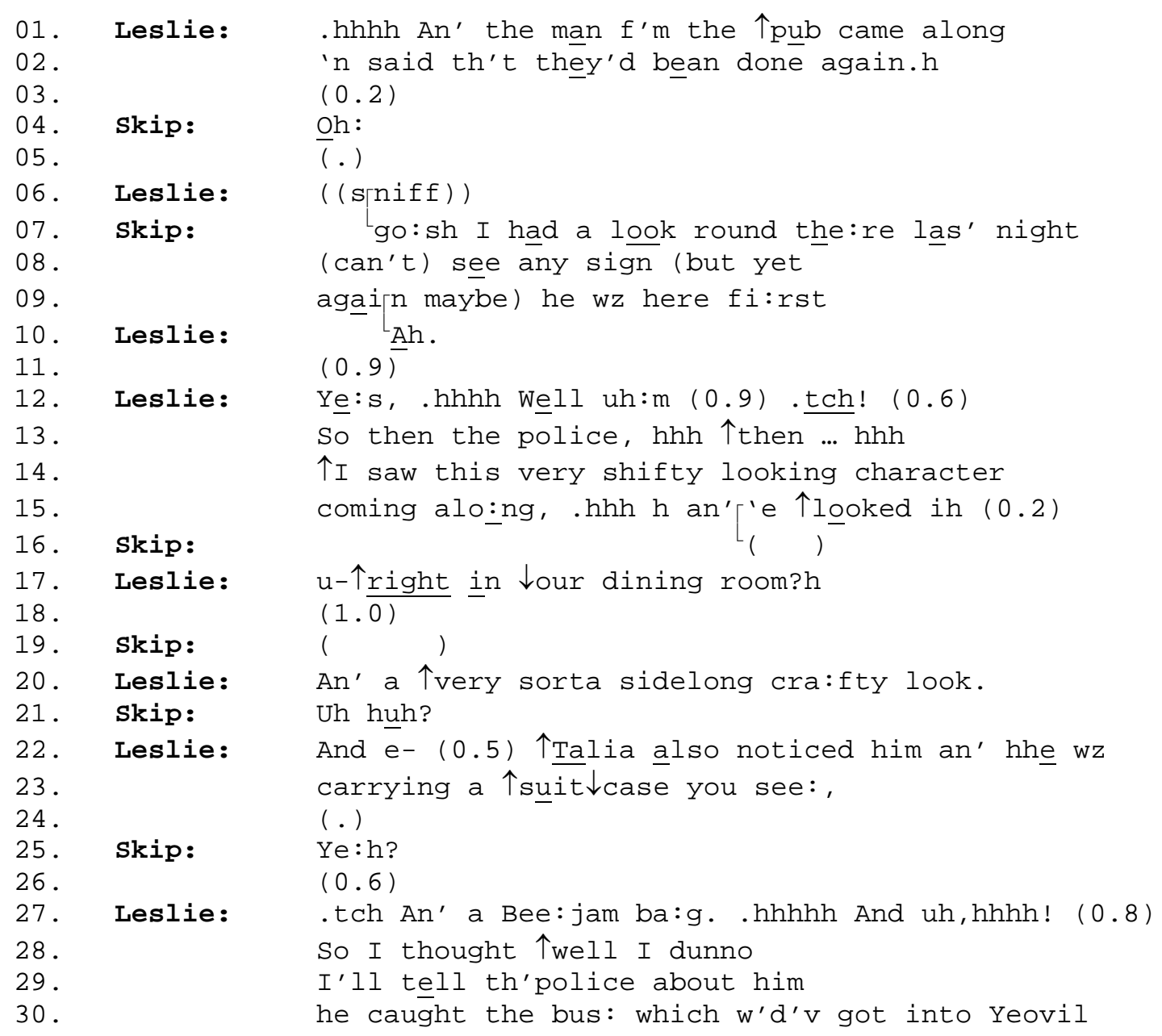


31.

32.

33.

34.

35.

36.

37.

38. about ten .hhh (0.4) thi:rty an' it wz then

about ten o'clock.h

Ye:s,

Leslie:

.hhhh So $\uparrow \underline{I}$ : wandered round $t^{\prime} t h \downarrow$ pub becuz they

were there then, hh

Mmhm?

Skip:

Leslie:

.hhhh $\uparrow A n^{\prime}$ they $\uparrow$ didn' n个anything about ou: $r$ burglary hheh heh!

(Holt:X(Christmas)2: Side 1: Call 6 pp. 2-3)

In terms of my discussion of widespread assumptions in discourse research, there is the reality of persons, events etc. ('context') and the inner world of knowledge, motivations and mental processes ('cognition'). What I want to pick out in particular here is the description of the 'character' who is reported to the police, and the description of the act of reporting itself. So, put simply, my start point will be some bit of reality (the 'character') and some bit of cognition (Leslie’s 'knowledge’). My suggestion will be that descriptions of both of these things are oriented to action; in a sense they formulate context and cognition, but as analysts we would be well advised to avoid treating them as separable items that can be correlated with action.

Let me start with the idea that these speakers are part of a culture where reporting someone who has not committed a crime to the police is potentially a delicate matter. It may make you vulnerable to be treated as a snitch, a busybody, or even as paranoid. That is, this is an activity where the actor's motivation is particularly vulnerable to question. If this were the case, we might expect to see evidence of this in the way the activity is reported. Here I suggest we can see this evidence in the description of the character and of the speaker's cognitive processes prior to the reporting.

A first description is offered in line 14; the person is a 'very shifty looking character'. The word shifty does a lot of work here ('given to evasions', 'furtive in character' appear in the 
Collins dictionary). It is a description that delivers dishonesty with it. But note that 'shifty looking' does not go beyond the evidence given; it displays that the speaker has not jumped to the conclusion that the person is, necessarily, actually shifty.

In lines 14, 17 and 20 contain descriptions of actions. The initial description 'looked in' is upgraded to 'right in' the dining room. And the description of the look is further upgraded as 'very sorta sidelong crafty’. In lines $22-3$ and 27 a further descriptive particular is provided. The person was carrying a 'suitcase' and a 'Bejam bag' (Bejam is a supermarket chain).

What is particularly interesting here is the way these external descriptions suggest motivations on the part of the person. As well as looking 'shifty', the 'sidelong' into the dining room in a 'crafty’ way suggests planning and surreptitious intentions. This fits with the suitcase and supermarket bag. A potential thief is likely to need something to carry their stolen goods in. The observation of there being two different kinds of bag is particularly neat. Someone with a supermarket bag is likely to have done their shopping; someone with a suitcase may be travelling. Both types of bag together are not tied to a conventional category in this way. But they are certainly consistent with a criminal who may be improvising ways of carrying goods. These methods for producing inferences via descriptions and categories were, of course, been a major topic of Harvey Sack’s early lectures (Sacks, 1992) and the work on membership categories that done since (e.g. Hester \& Eglin, 1997; Jayyusi, 1984).

Descriptions of this kind, then, do not allow for easy distinctions between the outer world and people's inner life, between cognition and reality. These 'external' descriptions suggest, more or less directly, a range of 'inner' or cognitive processes. 
So far I have concentrated on the nature of the descriptions in a rather abstract way. However, their sequential unfolding is relevant to my suggested analysis. Skip takes a number of brief turns during the description of the 'shifty character' (lines 16, 19, 21, 25). However, it is notable that he does not provide news receipts, second assessments or displays of affiliation. The only audible responses he makes are the neutral continuers on lines 21 and 25 (Schegloff, 1982). For example, Leslie’s strongly upgraded ‘very sorta sidelong crafty look’ on line 20 comes after her previous description of the suspicious look had been responded to only by a one second pause and an inaudible response from Skip. He does not provide a vigorous news receipt and or assessment or affiliation; nothing like the potential: 'oh god, so d'ya think that was our burglar'. So it is what Skip does not do that may occasion Leslie’s upgraded description in line 20. Then note that Skip’s response to the upgraded description in line 20 is 'uh huh?'. That is, he is still not providing a strong display of affiliation. And it is here, on line 20, that Leslie starts to give the suitcase description ('and e-`), but breaks off to offer the corroborating description 'Talia also noticed him'.

Note that after the suitcase description is delivered on line 23 Leslie says 'you see', which may be an attempt to establish shared knowledge (Edwards, 1997) or elicit an upshot. But again Skip comes back with a non-committal continuer ('yeh', line 25). It is after this that Leslie provides the suitcase and bag description. At the conclusion of this she does a long inbreath, the 'and uh', which possibly displays a failed search for something more to add, and then a long outbreath. All this is followed by a pause that is not filled by Skip. So again there is no second assessment, affiliation, or recognition of the upshot of the description. This is the environment in which Leslie delivers her description of informing the police. 
I started the discussion of this extract with the idea that in this culture it can be a delicate matter to report someone who has not committed a crime to the police. Part of this delicacy is displayed in the way the description of the putative thief is built in lines 14-27. The delicacy is also displayed in the way the reporting is described, and in particular the prefacing of this action in line 28. The upshot of the observation of the suspicious character is not 'so I told the police about him'. It is:

Leslie: $\quad$ So I thought $\uparrow$ well I dunno I'll tell th'police about him

That is, despite the rather elaborate working up of reasons to be suspicious of this person, they represent their action as equivocal (note the 'well' dispreference marker) and as based on uncertain or insufficient knowledge.

Wayne Beach (1997) has identified some interactional uses of 'claims to insufficient knowledge’ such as ‘I don’t know’. He shows some uses where participants can display uncertainly or neutrality, or can head off actions. In this case it is used in the report of an action that has already being performed. As a display of uncertainty I suggest that one of the things that 'well, I dunno' can do is soften the link that may potentially be heard lying between the action (informing the police) and noxious motivations that might arise from categories such as snitch, busybody or paranoid.

Some of its detailed characteristics may contribute to this. Note that it is 'I dunno' rather than the full 'I don’t know'. Without systematically examining a range of similar and contrasting examples it is no more than a suggestion; however, my sense from preliminary study is that 'I dunno' is a distinct phrase rather than an alternative pronunciation of 'I don't know' (see Potter, 1996, 1997 for further discussion of 'I dunno'). Note that it is commonplace to hear people say ‘she doesn't know', but 'she dunno’ sounds odd to me. 
Perhaps the running together of the words in this way is a display of casualness of thought, and this can be done sensibly about oneself but not about someone else. Whether this is right or not, the phrase can certainly soften a link between actions and motivations by tying the action to equivocation about relevant knowledge rather than having it arise directly from potentially problematic motivation (elsewhere I have written about this in terms of 'stake inoculation' - Potter, 1996). The point is not that some notion of knowledge is not relevant to the analysis, it is that knowledge and its insufficiency is being constructed for the action at hand and any discourse analysis needs to attend to this constructed and action oriented nature.

\section{CONCLUSION - CogNition As CONTEXT}

The point of this discussion has been to highlight the importance of treating cognition in much the same way as (other features of) context; as something that is formulated, worked up, constituted and oriented to by participants. Indeed, when dealing with actual materials it becomes hard to sustain any hard and fast analytic distinction between cognition and contextual reality; instead there are complex patterns of mutual implications. Describing someone as 'crafty’ and carrying bags provides for a particular motivation account. Prefacing a reported action with 'I thought well I dunno’ can head off available inferences about motivations that might be tied to that action. Cognition and reality blur together as talk unfolds; neither stand as a separable contextual frame against which to explain talk.

Cognition, reality and context are analysts' categories with their own history and tropology. It may be that the sorts of ontology they imply, and boundary work they perform, has been more constraining than helpful to social research. There is no reason why distinctions between them should necessarily be consequential for participants. Rather than legislating as 
to their implications prior to analysis, one of the themes in discursive psychology is precisely to study the varied contextual practices involving (what psychologists and other social sciences have treated as unproblematically) cognitive notions (Edwards, 1997). This does not involve a commitment to there being some unified, coherent and homogenous field of cognition.

This leaves a significant question with respect to the status of my own account. Is my account cognitive? After all, I have talked about motivation, stake, participants’ orientations and so on. Is my account a strategic account of what is going on, which relies on some notion of Leslie 'thinking out' how to deal with a delicate task? Beach and Metzger (1997) write of the strategic deployment of 'I don’t knows'. I would suggest that my analytic story of what is going on between Leslie and Skip is cognitive in the limited sense that it treats action in intentional terms, rather than brute movements or causal processes. And our language for talking about action is imbued with cognitivist connotations. To talk of Leslie's talk as managing the attribution of noxious motives seems to imply a strategic planner lying behind everything. However, I suggest that using this language to explicate action need not commit the analyst to cognitivism. That is, it need not commit the analyst to explaining what is going on terms of cognitive processes or events in the heads of actors.

In this case, for example, I would not expect that Leslie’s 'thought', or lack of firm knowledge, of the putative thief's criminal intentions, are mental entities that could be identified through some more technical psychological machinery (a questionnaire, a depth interview, protocol elicitation, a CAT scan). As to whether Leslie is strategically managing motive attribution or not, I am certainly not committed to some notion of Leslie consciously planning how to deal with this encounter. On the one hand, this seems rather unlikely for a 
casual telephone call (but see Heritage, 1990/1; Hopper, 1997). On the other, plans and goals start to become more insubstantial as cognitive objects when they come under close scrutiny (Edwards, 1997; Heritage, 1990/1; Suchman, 1997). To some researchers this may seem like an uncomfortable fudge; however, in my view is allows research to be conducted without the various confusions that I have tried to show follow from cognitivist approaches to discourse.

The general point, then, is that the notion of context as a mental construction in memory (van Dijk, 1997) or a set of hearer’s mental assumptions (Sperber \& Wilson, 1986) becomes problematic for the kinds of reasons that Schegloff adduces to problematize more sociological and sociolinguistic notions of independent context. In particular, close analysis reveals major difficulty in (a) separating cognitive context from ongoing participants constructions; (b) deciding what precisely counts as mental. This does not mean, however, that cognition ceases to be interesting. Just as the ethnomethodological cautions against adopting simple notions of determinate institutional contexts have not prevented a thriving body of discourse research on institutional talk, so discursive psychological cautions about cognitivism are not meant to take discourse researchers away from treating cognition in talk and text as a fertile topic for study. 


\section{REFERENCES}

Antaki, C. (1994). Explaining and arguing: The social organization of accounts. London and Beverly Hills, CA: Sage.

Antaki, C. (forthcoming) Identity-ascriptions in their time and place: "Fagin" and "The Terminally Dim”. In C. Antaki \& S. Widdicombe (Eds). Identities in Talk. London; Sage.

Beach, W.A. \& Metzger, T.R. (1997) Claiming insufficient knowledge. Human Communication Research, 23, 562-88.

Billig, M. (1987). Arguing and thinking: A rhetorical approach to social psychology. Cambridge: Cambridge University Press.

Billig, M. (1992). Talking of the royal family. London: Routledge.

Cook, G. (1990). Transcribing infinity: Problems of context presentation. Journal of Pragmatics, 14, 1-24.

Coulter, J. (1983). Contingent and a priori structures in sequential analysis. Human Studies, 6, 361-376.

Coulter, J. (1990). Mind in action. Oxford: Polity.

Coulter, J. (1991). Cognition: Cognition in an ethnomethodological mode. In G. Button (Ed.), Ethnomethodology and the human sciences. Cambridge University Press.

Drew, P. \& Heritage, J.C. (1992). Analyzing talk at work: An introduction. In P. Drew \& J. Heritage (Eds), Talk at work: Interaction in institutional settings (pp. 3-65). Cambridge: Cambridge University Press.

Drew, P. (1995a). Conversation analysis: The sequential analysis of intersubjectivity in conversation. In J. Smith, R. Harré, L. van Langenhove, \& P. Stearns (Eds.), Rethinking methods in psychology. London and Beverly Hills, CA: Sage. 
Drew, P. (1995b). Interaction sequences and 'anticipatory interactive planning.' In E. Goody (Ed.), The social origins of human intelligence. Cambridge: Cambridge University Press.

Edwards, D. (1994). Script formulations: A study of event descriptions in conversation. Journal of Language and Social Psychology, 13, 211-247.

Edwards, D. (1997). Discourse and cognition. London and Beverly Hills, CA: Sage.

Edwards, D. (forthcoming) The relevant thing about her. In C. Antaki \& S. Widdicombe (Eds). Identities in Talk. London; Sage.

Edwards, D. \& Potter, J. (1992). Discursive psychology. London: Sage.

Edwards, D. \& Potter, J. (1993). Language and causation: A discursive action model of description and attribution. Psychological Review, 100, 23-41.

Goodwin, C. \& Duranti, A. (1992). Rethinking context: An introduction. In A. Duranti \& C. Goodwin (Eds.), Rethinking context: Language as an interactive phenomenon (pp. 142). Cambridge: Cambridge University Press.

Heritage, J.C. (1984). Garfinkel and ethnomethodology. Cambridge: Polity.

Heritage, J.C. (1990/1). Intention, meaning and strategy: Observations on constraints in interaction analysis. Research on Language and Social Interaction, 24, 311-332.

Heritage, J.C. (1997) Conversation analysis and institutional talk: Analysing data. In D. Silverman (Ed.) Qualitative research: Theory, method and practice (pp. 161-182) London; Sage.

Heritage, J.C. \& Greatbatch, D.L. (1991). On the institutional character of institutional talk: The case of news interviews. In D. Boden \& D.H. Zimmerman (Eds.), Talk and social structure: Studies in ethnomethodology and conversation analysis (pp. 93-137). Oxford: Polity. 
Hester, S. \& Eglin, P. (Eds)(1997) Culture in Action: Studies in membership categorization analysis. Washington, D.C.; International Institute for Ethnomethodology and Conversation Analysis \& University Press of America.

Hopper, R. (1997) A cognitive agnostic in conversation analysis: when strategies happen in spoken interaction, paper presented at International Communication Association preconference on Discourse and Cognition, Montreal, May.

Jayyusi, L. (1984). Categories and the moral order. London: Routledge.

Lynch, M. \& Bogen, D. (1996). The spectacle of history: Speech, text and memory of the Iran-Contra hearings. Durham, NC: Duke University Press.

Mandelbaum, J. \& Pomerantz, A. (1990). What drives social action? In K. Tracy (Ed.), Understanding face-to-face interaction: Issues linking goals and discourse (pp. 151166). Hillsdale, N.J.; Lawrence Erlbaum.

Pomerantz, A. (1990/1991) Mental concepts in the analysis of social action, Research on Language and Social Interaction, 24, 299-310.

Potter, J. (1996). Representing reality: Discourse, rhetoric and social construction. London; Sage.

Potter, J. (1997) 'Discourse analysis as a way of analysing naturally occurring talk’ In D. Silverman (Ed.) Qualitative Research: Theory, method and practice (pp. 144-60) London; Sage.

Potter, J. (forthcoming) Discursive social psychology: From attitudes to evaluations, European Review of Social Psychology.

Potter, J. \& Wetherell, M. (1987). Discourse and social psychology: Beyond attitudes and behaviour. London: Sage. 
Schegloff, E.A. (1982). Discourse as an interactional achievement: Some uses of 'uh huh' and other things that come between sentences. In D. Tannen (Ed.), Analyzing discourse, text and talk (pp. 71-93). Washington DC: Georgetown University Press. Schegloff, E.A. (1987). Between micro and macro: Contexts and other connections. In J. Alexander, B. Giesen, R. Münch, \& N.J. Smelser (Eds.), The micro-macro link (pp. 207-234). Berkeley, CA: University of California Press.

Schegloff, E.A. (1989). From interview to confrontation: Observations on the Bush/Rather encounter. Research on Language and Social Action, 22, 215-240.

Schegloff, E.A. (1991). Reflections on talk and social structure. In D. Boden \& D.H. Zimmerman (Eds.), Talk and social structure (pp. 44-70). Berkeley: University of California Press.

Schegloff, E.A. (1992a). In another context. In C. Goodwin \& A. Duranti (Eds.), Rethinking context. Cambridge: Cambridge University Press.

Schegloff, E.A. (1992b). On talk and its institutional occasions. In P. Drew \& J. Heritage (Eds.), Talk at work: Interaction in institutional settings. Cambridge: Cambridge University Press, pp. 101-134.

Schegloff, E.A. (1997) Whose text? Whose context?, Discourse and Society, 8, 165-187.

Sperber, D. \& Wilson, D. (1986) Relevance: Communication and cognition. Oxford; Blackwell.

Suchman, L. (1987). Plans and situated actions: The problem of human-machine interaction. Cambridge: Cambridge University Press.

van Dijk, T.A. (1997) Discourse as interaction in society. In T.A. van Dijk (Ed.) Discourse as Social Interaction (Vol. 2 of Discourse Studies: A multidisciplinary introduction). London; Sage.

Watson, G. \& Seiler, R.M. (Eds.) (1992). Text in context. London: Sage. 
Wetherell, M. \& Potter, J. (1992) Mapping the Language of Racism: Discourse and the legitimation of exploitation. London; Harvester, New York; Columbia University Press.

Widdicombe, S. \& Wooffitt, R. (1995). The language of youth subcultures: Social identity in action. Hemel Hempstead, UK: Harvester/Wheatsheaf.

Wieder, D.L. (1974). Language and social reality. The Hague: Mouton. 